\title{
A Criação de Sensibilidades: Epistemologia e Método na Psicologia Analítica
}

\author{
Liliana Liviano Wahba* \\ Pontificia Universidade Católica de São Paulo, São Paulo, SP, Brasil
}

\begin{abstract}
RESUMO - O artigo propõe uma revisão teórica da contribuição de C.G.Jung na história da psicologia e no rol das ciências humanas. O percurso adotado desenvolve o conceito de equação pessoal e a relevância do mesmo na teoria sobre os tipos psicológicos. Elucida, ainda, como esse pressuposto se insere em uma epistemologia e método da psicologia analítica, a partir dos princípios formulados por Jung. Conclui-se que o fazer nas ciências humanas, sob o prisma desse enfoque, está atrelado a um método que respeite a subjetividade do pesquisador e a integridade do sujeito de pesquisa, imbuído de princípios epistemológicos, tais como estrutura da psique, finalismo e sincronicidade e permeado por uma linguagem simbólico-metafórica que reúne imagem e palavra em narrativas de significado.
\end{abstract}

PALAVRAS-CHAVE: epistemologia, psicologia analítica, equação pessoal, processamento simbólico, método

\section{Creating Sensitivities: Epistemology and Method in Analytical Psychology}

\begin{abstract}
The article proposes a theoretical revision of the contribution of C.G.Jung for the history of Psychology and its role in Human Sciences. The adopted perspective develops the concept of personal equation and its relevance for the theory of psychological types. It also elucidates the epistemology and method of analytical psychology departing from Jung's theoretical principles. The conclusion states that the making of science in psychology under such perspective is linked to a method that respects the researcher's subjectivity and the integrity of the subject of research, imbued with epistemological principles such as psychic structure, finalism and synchronicity, and it is permeated by a metaphorical symbolical language that unites image and words in meaning narratives.
\end{abstract}

KEYWORDS: epistemology, analytical psychology, personal equation, symbolic processing, method

Carl Gustav Jung foi um pensador teórico e clínico profícuo, sujeito a controvérsias, principalmente devido à ruptura com Freud e a seus postulados sobre religiosidade, inconsciente coletivo e arquétipos. Há inúmeros textos que relatam fidedignamente os fatos históricos, entre os quais são recomendados Carl Gustav Jung: Avant-garde conservative, de Jay Sherry (2010), o livro sobre evolução da psiquiatria dinâmica de Ellenberger (1970), o Manual de Cambridge para Estudos Junguianos (2002) e artigos de Grinberg (2004) e Wahba (2004).

É reconhecido como um nome notável na psiquiatria de início do século XX, expoente principal do renomado hospital psiquiátrico Burghölzli, na Suíça e colaborador direto de Eugene Bleuler, ambos dedicados ao estudo e tratamento da daemencia praecox, depois denominada de esquizofrenia por Bleuler. Há de ser lembrado que o nascimento da moderna psiquiatria dinâmica deve-se ao trabalho com pacientes psicóticos de Pierre Janet, Eugene Bleuler, Carl G. Jung (Ellenberger, 1970).

Quase desconhecido, no entanto, é o seu investimento apurado e contínuo no decorrer de anos em prol da constituição de uma Psicologia de cunho científico e de caráter unificado, reunindo ideias e pressupostos de outros teóricos de relevância da época. A esse respeito, uma revisão

\footnotetext{
*E-mail: lilwah@uol.com.br

- Submetido: 04/08/2015; Revisado: 20/01/2017; Aceito: 20/06/2017.
} 
completa e consistente foi realizada por Shamdasani (2006), em Jung e a construção da psicologia moderna.

O primórdio do mundo moderno caracteriza-se por uma mudança na consciência coletiva e Jung foi pioneiro em trazer esse aporte para a psicanálise. Uma revolução da consciência ocorreria no final do século XIX, para a qual o pensamento de Jung viria a contribuir com uma avaliação crítica da condição humana, no qual alia a atitude científica rigorosa à filosofia de vertente romântica alemã que se volta ao irracional e à exploração do desconhecido em seus diversos fenômenos psíquicos. Ciente da efervescência criativa do final do século XIX e estudioso da filosofia oriental e ocidental, da história das religiões, da antropologia, permanece atento às descobertas na medicina, na física e às inovações na arte.

Jung se permitia explorar a religiosidade, as artes, a mediunidade, os limites do transcendente (Douglas, 2002; Hauke, 1998). Autores como Progoff (1953), Zoja (2005), Dawson (2002), Hauke (1998), Sherry (2010), entre outros, destacam sua inserção cultural, a extensão do complexo psicológico, a sua vertente histórico-cultural, a compreensão de Jung que se aplica às crises de determinada época e cultura, as condições sociopolíticas que requerem consciência de transformações nos planos individual e social, a influência de sua teoria na linguagem artística e cultural de nossa época, a concepção da dimensão histórica dos símbolos, a interpenetração do fenômeno psíquico em sua materialidade e espiritualidade. Nas palavras de Progoff (1953, p. 221), "Ele desenvolveu uma concepção da natureza cognitiva do ser humano" e, principalmente, de acordo com Barreto (2008), buscou recuperar para a consciência moderna a sensibilidade simbólica, uma possível saída para o niilismo ético.

O presente artigo propõe assinalar alguns princípios epistemológicos que embasam o método junguiano, aplicáveis ao conhecimento da psicologia - particularmente na pesquisa - no rol das Ciências Humanas e de sua transformação.

\section{CIÊNCIA E PSICOLOGIA, O INDIVIDUAL E O COLETIVO}

Jung, como apontado, cria sua teoria no contexto da condição moderna de sua época, com crítica ao materialismo científico vigente. Sua contribuição é essencial para a fundamentação da psicologia como corpo de conhecimento na ciência moderna nos primórdios do século XX. Refutou a psicologia acadêmica de cunho experimental como unívoca e prioritária e, segundo Jones (2007), teve o vislumbre a respeito da emergência do significado como objeto das ciências humanas, particularmente da psicologia. A autora, apesar de assinalar diferenças epistemológicas, credita a Jung uma vertente pós-moderna no realce às experiências significativas para o ser humano, o qual fora anunciado por Hauke (1998) ao atribuir à sua teoria uma revisão pós-moderna do espírito humano, acompanhando o desenvolvimento da ciência, das artes e da sociedade.

Atento ao status da psicologia científica, em que um dos maiores desafios era diferenciar o individual e o geral, com a obra Tipos Psicológicos - uma revisão da história do pensamento - visou postular uma Psicologia Geral, desafio que permanece expresso até seus escritos tardios. Posto que o geral é requisito de toda ciência, a psicologia se manteria sempre individual na prática e geral na teoria científica.

Frente ao desafio da psicologia, que devia lidar com o homogêneo universal e com as particularidades heterogêneas da consciência, teorias de tipos psicológicos surgiram para procurar compreender algumas características que agrupassem individualidades e modos de pensamento. Mas, ainda que se encontrassem pessoas com certas tendências de funções psicológicas e de atitudes em comum, teorias específicas teriam mais aceitação para cada grupo e, portanto, a questão não resolvida continuava, pois, se cada autor atraísse aqueles que se identificassem com sua tipologia, poucos conceitos manteriam validade universal.

Jung via, nesse dilema, a antiga distinção irresolúvel entre ciências humanas e naturais e nos últimos escritos a respeito desse debate, ele afere que, apesar de não haver garantias de uma explanação certeira, a psicologia observa como os processos psíquicos vêm à consciência, subjazendo, portanto, a todas as ciências. Em 1957, em "Presente e futuro" (Jung, 1978a), continua a discussão a respeito dos métodos estatísticos aplicados à psicologia e a diferenciação entre o único da individualidade e o geral explicativo das ciências. Contrapõe a compreensão do individual e ao conhecimento da teoria, consistindo o método, na psicologia médica, em remeter o postulado das questões ao próprio objeto de estudo, sem que o experimentador as escolha de modo livre e arbitrário.

Jung propõe que se responda à problemática advogando a necessidade de um equilíbrio entre compreensão e conhecimento e assevera que o valor heurístico de uma teoria se fundamenta em sua aplicabilidade e na possibilidade de estabelecer alguma predição. Certamente, fica sem resposta a atribuição de caráter científico à psicologia, dilema que o autor encerra de modo original: a ciência, ao nascer na psique do pesquisador, depende, em última instância, da psicologia, pois a psique é "a mãe de todas as tentativas de compreender a Natureza" (carta a E.A. Bennet; Adler \& Jaffé, 1975, p. 567).

Posto que todo conhecimento é sujeito à constelação psicológica subjetiva do investigador, Jung (1976a, para. 9) traz o conceito de "equação pessoal", que denota a existência de uma subjetividade inerente a todo ponto de vista, de modo que irá propor uma teoria dos determinantes 
subjetivos da equação pessoal. Vê-se, portanto, que a obra Tipos Psicológicos, que somente tem um de seus capítulos destinado à tipologia - mais do que uma caracterologia-, busca apreender, na medida do possível, alguns componentes subjacentes de modos de conhecer, que pudessem, de certa forma, tornar compreensível a multiplicidade da apreensão.

Apesar de que poucos possam pensar que a psicologia possa ser escrita ex cathedra, atualmente a maioria de nós está convencido que uma psicologia objetiva deve ser fundada sobretudo na observação e experiência. Esse fundamento seria o ideal desde que isso fosse possível. (Jung, 1976a, para. 9)

Participa, portanto, do debate a respeito da subjetividade do cientista, que de acordo com Morin (2000), precisava ser restaurada, posto que o sujeito havia se tornado invisível no paradigma da objetivação e da explicação e se perdera o elo entre produto e produtor. Rocha Filho (2003) e Hauke (1998) retraçam as descobertas no campo da física quântica no século XX - que Jung acompanhava -, em que conceitos como probabilidade, relatividade e incerteza demoliam a imutabilidade e reconhecia-se a influência do observador sobre o fenômeno observado, ou seja, o sujeito contribuía para construir a realidade. O estudioso de paradigmas científicos, Thomas Kuhn (1973), estabelece alguns critérios de objetivação, mas entende que, de fato, serão referendados pela valoração subjetiva do pesquisador, que depende de características pessoais e da inserção histórica.

Perante à dualidade objetivo-subjetivo ou nominalismo - realismo, Jung propõe uma combinação no processo psicológico, o esse in anima, constituinte da realidade viva, pois só podemos perceber imagens formadas em nossa mente. Seria essa a entrada para a magnitude e pujança da formulação simbólica em sua teoria, como será apresentado posteriormente.

Um componente importante da subjetivação e da comunicação referia-se à linguagem usada. No Congresso de Psicologia Experimental de Genebra, em 1909, distintos pensadores alertavam que a psicologia denotava confusão no uso de termos e que deviam investir na procura de uma nomenclatura mais unificada.

Em Tipos Psicológicos, Jung (1976a) acrescenta as Definições para elucidar os conceitos empregados. A atenção à linguagem seria importante em distintos momentos de sua obra, por exemplo, nos estudos de Associação de Palavras com famílias, em que reconhece estruturas linguísticas comuns. Dada a ênfase ao simbólico e imagético, sua atenção estendeu-se à linguagem irracional, distinção entendida na psicanálise entre um pensamento dirigido, mais racional e objetivo e outro não dirigido, permeado pela livre fantasia.

Um estudo sobre a linguagem na obra de Jung foi realizado por Schmitt (2011), no qual se verifica a modulação da linguagem e sua interface entre pensamento dirigido e não dirigido: a linguagem é veículo de expressão de ambas as modalidades de pensar. E, ainda, atitudes se baseiam inconscientemente em sentenças linguísticas, nas quais afetos se associam a conceitos que adquirem poder de atração (Jung, 1978b). O componente emocional não racional está, portanto, imbricado ao componente conceitual, outro aspecto de caráter inovador à luz das teorias da neurociência posteriores ao autor.

A complexidade da linguagem acrescia a dificuldade de unificar postulados científicos e, dada a diversidade de nomenclaturas e restrição de compreensão - que não podia ser garantida a partir de diferentes teorias e pontos de vista -, Shamdasani (2006) assinala um fator relevante:

Independentemente de que aquilo a que esses conceitos se referem exista ou não, eles sem dúvida transformaram a experiência subjetiva ao reformatar a linguagem usada para falar sobre isso e criaram uma nova forma de sensibilidade. (p. 80)

\section{PRINCÍPIOS EPISTEMOLÓGICOS}

Em toda atividade científica, a episteme - conhecimento teórico -, alia-se à techne - arte, técnica, prática. A teoria de um autor, portanto, reflete-se no método empregado para investigação. O método junguiano aporta algumas características que decorrem da teoria - epistemologia - que lhe é subjacente.

Shamdasani (2006) expõe que Jung embasou seu método científico e terapêutico na teoria do pragmatismo e do pluralismo de William James, implicando que sempre haverá algo inatingível no conhecimento. No entanto, Jung depois abandonará o pragmatismo, ainda que mantivesse os princípios da sabedoria prática. Barreto (2012) refere ao princípio filosófico para a psicoterapia em Jung - que pode ser aplicado para a atividade científica - da "sabedoria prática" (p. 56), que visa alcançar a realização da natureza humana, buscada no aqui e agora de cada situação.

Jung desafiou os dogmas da psicologia acadêmica do século XX segundo os quais só se validava o método de experimentação e estatístico. Considerava que tal método impõe condições limitantes à natureza, forçando-a a dar respostas às questões formuladas pelo homem e afetadas por um viés psicológico. Sem negar a experimentação e a causalidade, postula que essas são insuficientes para a compreensão do fenômeno psíquico e como esse se expressa em cada indivíduo, pois o princípio da causalidade seria apenas relativamente válido. Os estudos sobre sincronicidade, particularmente estimulados por sua vinculação com a física quântica e sua amizade com Wolfgang Pauli, nos anos 30, o levaram a realçar o continuum matéria-espírito. No texto 
sobre "Sincronicidade", Jung (1978c) advoga a possibilidade de eventos acausais.

Em suma, o dilema da subjetividade acompanha o dilema de se postular a psicologia como ciência - veja-se o individual e o geral -, e aqui a coerência do pensador se revela ao expressar que se abandona a busca do verdadeiro ou correto para produzir a "verdadeira expressão", aquilo que é percebido subjetivamente.

Para o propósito da psicologia, penso que o melhor é abandonar a noção de que possamos estar numa posição que permita fazer afirmativas sobre a natureza da psique que seja "verdadeira ou "correta". O melhor que podemos alcançar é verdadeira expressão. Por verdadeira expressão entendo uma confissão aberta e uma apresentação detalhada de tudo que é subjetivamente observado. (Jung,1979, para. 771)
No entanto, tal subjetividade, tomada ao extremo, levaria a observações erráticas sem rumo e o autor repetidamente demonstrou a importância de referenciais norteadores, asseverando, contudo, que toda verdade é transitória, posto que novos conhecimentos eventualmente virão substituí-la. Se, de acordo com Morin (2000, p. 19), "conhecer é dialogar com a incerteza", para a construção do conhecimento, tanto na clínica, como na pesquisa, não deixam de ser necessários a formulação e o método.

Destacam-se, a seguir, pontos focais na epistemologia da psicologia analítica: estrutura, finalismo, linguagem e imaginário simbólico, acrescido ao fundamento ético essencial a toda atividade científico - clínica.

\section{ESTRUTURA DA PSIQUE}

Samuels (2008) assinala a visão estrutural do inconsciente, compartilhada por psicanalistas como Klein, Lacan, Spitz e Bowlby e, ainda, que esse se estruturaria, até certo ponto, como uma linguagem, como postulado por Lacan. A capacidade autorregulatória teria sua procedência nessa fundamentação estrutural e, consequentemente, a psique seria provida também de um propósito criativo, não somente destrutivo e caótico. O autor vê, nos postulados de Jung, uma antecipação de ramificações posteriores de teorias que incluem o componente criativo como matriz. Assim, cita paralelos em Winnicott sobre o brincar e nas teorias psicológicas humanista de Maslow e de Rogers, as quais podemos acrescentar Viktor Frankl. Hoje em dia, na interface de neurociências e psicanálise, entre alguns expoentes, temos, Alan Schore (2003), Daniel Stern (1985) e Jean Knox (2011), que descrevem sistemas neurais em níveis sobrepostos de complexidade, para a regulação do eu mediante empatia e apego, promovendo autonomia, liberdade e autoeficácia (Wahba, 2012).

Casey (1987) compara o conceito de psique objetiva à teoria estruturalista da linguagem, assim como Papadopoulos (2006). Haveria uma base coletiva da imagem e da palavra, uma fundamentação transpessoal "enraizada na ação espontânea da psique" (p 105), representando uma atividade simbólica coletiva.

O pressuposto estrutural apoia-se na teoria dos arquétipos que, em si, constituem pura abstração. Trata-se, para Jung, de um modo de nomear aquilo que subjaz à modulação universal da psique de seres humanos, por sua vez, um contínuo na escala da evolução. Seria um modo de apreensão universal, comum à espécie, que corresponde à ação instintiva no plano do imaginar. Ou seja, por termos cérebros anatomicamente e organizacionalmente semelhantes, teremos formas mentais basicamente semelhantes. Constitui, no entanto, um equívoco - cometido com frequência - atribuir uma personificação ou um determinismo de pensamento ou de ação aos arquétipos. Esses são somente princípios organizacionais que embasam distintas manifestações, conforme o meio histórico-cultural e a experiência pessoal. Compreende-se o substrato arquetípico como um fato emergencial contextualizado conforme o momento de sua manifestação.

$\mathrm{O}$ assinalamento coletivo na formulação da teoria arquetípica responde, em parte, à busca enunciada de alguns componentes identificáveis para uma teoria geral e universal em psicologia.

\section{FINALISMO}

Papadopoulos (2006) destaca a função teleológica/ finalista do conhecimento, entendida metodologicamente como uma finalidade construída à medida que o conhecimento se gera. Nesse ocorre uma observação participante, uma construção do conhecimento em interação.

A teleologia aproxima-se do conceito de causa final segundo Aristóteles, ou seja, para qual fim a ação se move. Em Jung, associa-se a explanação estrutural e sincronística do funcionamento psíquico com a possibilidade de emergência de significados e de conexões acausais, imbuídas, em última instância, de um objetivo autorregulador.

A estrutura da psique fundamenta a emergência de significados que somente podem ocorrer de modo contingente, provendo conexões significativas, ou seja, uma epistemologia contextualizada que não perde sua finalidade.

Importa entender a finalidade, em Jung, de modo processual, modulado pela experiência, não dada aprioristicamente. Em diversos escritos, o autor enfatiza 
tal diferenciação, contrária à concepção corrente de que se "contém a ideia de um fim ou alvo antecipado" (Jung, 1978d, p. 4), preferindo o termo finalismo a teleológico. O finalismo está atrelado à concepção da psique promotora de um processo de autossustentação compensatória, visando ao melhor alcance possível de sua plenitude.

Outros psicólogos da atualidade denotaram a função antecipatória da psique e da imaginação, aproximando-se de uma compreensão finalista. Moreira Leite (1987) destaca que, além da função compensatória para as frustrações, apontada por Freud (1976), muitas fantasias apresentam uma "predição da experiência" (Moreira Leite, 1987, p. 87) e preparam para a realidade, permitindo estabelecer etapas para objetivos futuros. E mais, há fantasias que o autor denomina criadoras, que constituem uma "forma de reestruturar ou recriar a realidade" (p. 88). Autores junguianos certamente concordam com tal concepção, diga-se, antevista por Jung quando as primeiras teorias da psicologia profunda eram formuladas.

\section{O IRRACIONAL,A IMAGINAÇÃO,A METÁFORA E O SÍMBOLO}

Jung se distancia do pragmatismo e considera o irracional, entendido menos como antirracional e mais como “extrarracional", isto é, o que não se pode fundamentar na razão (Jung, 1976, para. 774)1. Conclui que o pragmatismo leva à resignação e à secura da criatividade e que o conflito dos opostos não poderia ser resolvido mediante a conceitualização, nem pela assertiva pragmática do valor prático de pontos de vista irreconciliáveis, mas somente via "um ato positivo de criação que assimila os opostos como elementos necessários de coordenação" (Jung, 1976, para. 541).

Importa destacar a perspectiva junguiana de conjugação entre o ego - centro da consciência- e o desconhecido inconsciente -, sem uma entrega às cegas ao irracional, o que constitui a essência do processo denominado de função transcendente, a operação que possibilita uma mudança de atitude, uma nova perspectiva mediadora entre instâncias opostas, "corporificando o esforço do inconsciente para a luz e o esforço da consciência para a substância". (Jung, 1978e, para. 168). A mediação é possibilitada pela emergência de produtos espontâneos da psique, os símbolos, que constituem a melhor expressão possível de algo relativamente desconhecido.

Jung certamente enfatizou uma função prospectiva simbólica, mas não deixava de assinalar o componente regressivo, as fantasias infantis que não produzem transformação e que necessitam ser trabalhadas. Alertava, também, para "as ilusões sobre a beleza da alma" (1978f), ou seja, a negação dos componentes sombrios da personalidade, mascarados por ideais de pureza a respeito da natureza do ser.

Adams (2004) e Colman (2006) são autores pósjunguianos que diferenciam, na prática clínica, a manifestação de distintos tipos de fantasia e, esse último, destaca a distinção entre uma "imaginação" e um "imaginário", em que a imaginação autêntica necessita se defrontar com a falta, sem escapismos ilusórios onipotentes que procuram evitar a constatação da própria fragilidade.

\section{A ÉTICA DO CONHECIMENTO}

Jung é um pensador que enfatizava a fundamentação ética do conhecimento, no volume 10 das Obras Completas - Civilização em transição, com maioria de escritos após a II Guerra - e na catástrofe que resultou da ciência aplicada ao terror -, essa ênfase ética é ressaltada, vinculando a consciência individual à comunidade ética. Aparece, entretanto, desde os primeiros textos, quando descreve o procedimento da imaginação ativa com sua vertente estética e compreensiva, às quais não pode faltar o componente de responsabilidade ética, ou seja, o que se faz com o que se descobre a respeito de si. Em Memórias, sonhos, reflexões (1961), enfatiza que o insight que decorre do trabalho simbólico imagético deve-se converter em obrigação ética.

$\mathrm{Na}$ atividade científica, podemos inferir, a partir do autor, ser necessária profunda consciência do presente, evitando "precipitação desenfreada para o novo" (Jung, 1961, p. 210). Diante da falta de sentido contemporânea que leva à neurose, Jung se refere aos riscos de descobertas científicas, ainda que brilhantes. Em "Presente e futuro", denunciava a massificação do método estatístico acompanhando o Homo consumericus, sujeito ao hiperconsumo e à massificação. Ou seja, os sistemas impessoais que imperavam no domínio social, no mercado e nas técnicas, também dominariam os sistemas de produção de conhecimento.

1 A distinção feita por Ortega y Gasset (1958) elucida essa temática. Diferencia razão de racionalismo, pois a primeira se fundamenta e finda no irracional, o segundo impõe um modo de ser. 


\section{METODOLOGIA EM PESQUISA: ALGUNS PARÂMETROS}

Jung critica as limitações do método experimental, mas propõe que esse seja ampliado em vez de abolido, pois, segundo ele, permanecer exclusivamente no modelo experimental positivista e empirista deixa de levar em conta o irracional. "A natureza é impedida de responder a partir da plenitude de suas possibilidades, já que essas possibilidades são restringidas ao que seja praticável" (Jung, 1978c, para. 864). Ele enfatiza a experiência do humano e, quando se autodenomina empírico, sua referência é a realidade psíquica, o esse in anima, a fantasia como constituinte da realidade humana. Para diminuir a restrição científica, Jung propõe que o método de inquérito não imponha condições que venham a deturpar o observado.

Evidencia-se tal pressuposto na denominação construtivo que dá a seu método empírico-comparativo, cujos conceitos necessitam ter utilidade prática em uma abordagem empírica e fenomenológica, por vezes denominada sintética/ hermenêutica, dada a leitura simbólica, mediante analogias, em que o símbolo não é propriamente interpretado, já que o significado está nele contido. Para compreendê-lo, a leitura é necessária, e Jung (1980) descreve o método do filólogo, que procura analogias, amplificações, para trazê-lo à consciência. A amplificação é um método comparativo que dimensiona o material simbólico na história da cultura.

A fim de elucidar o modo de apreender a realidade psíquica - que se encontra entre o objetivo e o subjetivo, na intersubjetividade -, parte-se de observação empírica do fenômeno pesquisado, classificando os dados até inferir uma correspondente teoria estrutural (Jung, 1976a). Penna (2013) operacionaliza o pensamento simbólico, que se dá mediante comparações e analogias entre diversas áreas do conhecimento. A compreensão dos fenômenos, ou seja, a análise do material coletado, é realizada por meio do processamento simbólico - cerne da obra de Jung -, que constitui a ferramenta chave da metodologia junguiana. Há uma integração das funções da consciência nesse processo, que promove uma produção de conhecimento de ordem intelectiva, perceptiva, valorativa e intuitiva.

Pode-se dizer que a compreensão do fenômeno, por meio da dimensão simbólica, alia a descrição, a experimentação - que adquire caráter de indagação em direção ao que não é revelado em primeira instância, apenas pelo observável - e a comparação ampliada, num circuito de busca de sentido hermenêutico.

Humbert (1996) explicita o método de Jung de se aproximar ao inconsciente, que foi descrito nos Seminários das visões (Jung, 1976b) e que pode ser aplicado a momentos do percurso do pesquisador. A consciência empreende três atividades: Geschehenlassen (deixar acontecer); Betrachten (considerar, impregnar) e, finalmente, Sich auseinanderstzen (confrontar-se com), ou seja, o ciclo inicia-se com a entrega e se encerra com a tomada de consciência do processo. Portanto, a fantasia, a imaginação criadora e a ativação da função intuição, permeadas por símbolos que representam a possibilidade de confluência do inconsciente com o consciente, aliam-se à observação apurada e à classificação do que é observado.

Pilard (2015) destaca que Jung resgata na ciência a intuição como uma função da consciência, a qual é ativada particularmente na fantasia criativa e no adentrar da dimensão inconsciente. A respeito da imaginação e da atividade de pesquisa, Romanyshyn (2007) credita à subjetivação do pesquisador um componente de entrega ao inconsciente, que se constitui sua "ferida de pesquisador", inerente a toda pesquisa empreendida com motivação genuína. Em inglês, re-search denota, segundo o autor, uma procura de alguma conexão perdida da alma, metaforicamente, o reencontro do mundo, a descoberta do novo e a recuperação de um modo de habitar.

\section{CONCLUINDO}

O pesquisador, portanto, atende às necessidades de sua época procurando soluções para o bem viver comunitário e individual. O senso ético da própria limitação vincula-se à constante consideração ao outro, o qual poderá ser apenas parcialmente apreendido.

A dificuldade de se conotar a psicologia como ciência, dada a particularidade de seu objeto de estudo, em que a psique do observador partilha da psique do observado, levou Jung a formular o conceito de equação pessoal: voltava sua atenção à atitude do pesquisador, que determina um fazer.

O fazer nas ciências humanas está atrelado, para o autor, a um método que respeite a subjetividade do pesquisador e a integridade do sujeito de pesquisa, imbuído de princípios epistemológicos, tais como estrutura da psique, finalismo e sincronicidade e permeado por uma linguagem simbólicometafórica, que reúne imagem e palavra em narrativas de significado.

Em suma, trata-se da possibilidade de modular a experiência e compartilhá-la. Zoja (2005) aponta que a grande revolução da psicanálise no mundo moderno foi a de ter criado uma nova subjetividade. E, podemos acrescentar, ter criado uma nova forma de sensibilidade para compreender nossa inserção no mundo, as relações com os outros, as tessituras da interioridade. Pesquisar é indagar: quem somos, como e onde estamos, como afetamos os demais e como por eles somos afetados, o que sonhamos e aspiramos, para onde nos dirigimos e como o fazemos. 


\section{REFERÊNCIAS}

Adams, M.V. (2004). The fantasy principle: Psychoanalysis of the imagination. New York: Brunner- Routledge.

Adler, G., \& Jaffé, A. (Ed). (1975). C G. Jung Letters -2, 1951-1961. Princeton: Princeton University Press.

Barreto, M.H. (2008). Símbolo e sabedoria prática. C. G. Jung e o mal estar da modernidade. São Paulo: Loyola.

Barreto, M.H. (2012). Pensar Jung. São Paulo: Paulus.

Casey, E. S. (1987). Jung and the post-modern condition. Spring. Texas: Spring Publications.

Colman, W. (2006). Imagination and the imaginary. Journal of Analytical Psychology, 51(1), p. 21-41.

Dawson, T. (2002). Jung, literatura e crítica literária. In P. Y. Eisendrath \& T. Dawson (Eds.), Manual Cambridge para estudos junguianos (pp. 239-260). Porto Alegre: Artmed.

Douglas, C. (2002). O contexto histórico da psicologia analítica. P. Y. Eisendrath \& T. Dawson (Eds.), Manual Cambridge para estudos junguianos (pp. 41-54). Porto Alegre: Artmed.

Eisendrath, P. Y., \& Dawson, T. (Eds.). (2002). Manual Cambridge para estudos junguianos. Porto Alegre: Artmed.

Ellenberger, H. F. (1970). The discovery of the unconscious. The history and evolution of dynamic psychiatry. New York: Basic Books Inc.

Freud, S. (1976). O estranho. In J. Strachey (Ed.), Edição standard brasileira das obras completas de Sigmund Freud. Vol. XVII (1917-1919). Rio de Janeiro: Imago. (Original publicado em 1919)

Grinberg, L. P. (2004). Jung à época do nazismo. Um capítulo na história das instituições psiquiátricas. Junguiana, 22, 59-68.

Hauke, C. (1998). Jung, modernity and postmodern psychology. In I. Alister \& C. Hauke (Ed), Contemporary Jungian analysis (pp. 278-298). New York: Routledge.

Humbert, E (1996). C. G. Jung: The fundamentals of theory and practice. Wilmette: Chiron.

Jones, R. (2007). Jung, psychology, postmodernity. New York: Routledge.

Jung, C. G. (1961). Memórias, sonhos, reflexões. Rio de Janeiro: Nova Fronteira.

Jung, C. G. (1976a). Psychological types. CW 6. Princeton: Princeton University Press. (Original publicado em 1921)

Jung. C. G. (1976b). Vision seminars [from 1930-1934]. Spring Publications. (Originais publicados em 1939/1941/1957)

Jung, C.G. (1978a). The undiscovered self (Present and future). In Civilization in transition. CW 10. Princeton: Princeton University Press. (Original publicado em 1957).

Jung, C.G. (1978b). Spirit and life. In The structure and dynamics of the psyche. CW 8. Princeton: Princeton University Press. (Original publicado em 1926)

Jung, C.G. (1978c). Synchronicity: An acausal connecting principle. In The structure and dynamics of the psyche. CW 8. Princeton: Princeton University Press. (Original publicado em 1952)

Jung, C.G. (1978d). On psychic energy. In The structure and dynamics of the psyche. CW 8. Princeton: Princeton University Press. (Original publicado em 1928)

Jung, C. G. (1978e). The transcendent function. In The structure and dynamics of the psyche. CW 8. Princeton: Princeton University Press. (Original publicado em 1916/1957)
Jung, C.G. (1978f). The spiritual problem of modern man. In Civilization in transition. CW 10. Princeton: Princeton University Press. (Original publicado em 1928/1931)

Jung, C.G. (1979). Freud and Jung: Contrasts. In Freud and Psychoanalysis. CW 4. Princeton: Princeton University Press. (Original publicado em 1931/1933)

Jung, C.G. (1980). The Tavistock Lectures. Lecture III. In The symbolic life. CW 18. Princeton: Princeton University Press. (Original publicado em 1935)

Kuhn, T. (1973). Objectivity, value judgment, and theory choice. Recuperado de <https://www.andrew.cmu.edu/user/kk3n/ philsciclass/kuhn.pdf $>$.

Knox, J. (2011). Self-agency in psychotherapy. New York: Norton. Morin, E. (2000). A cabeça bem feita: Repensar a reforma, reformar o pensamento. Rio de Janeiro: Bertrand Brasil.

Moreira Leite, D. (1987). Psicologia e literatura. São Paulo: UCITEC, Ed UNESP.

Ortega y Gasset, J. (1958). El tema de nuestro tiempo. Madrid: Revista de Occidente. (Original publicado em 1923)

Papadopolos, R. (2006). Jung's epistemology and methodology. In The handbook of Jungian Psychology: Theory, practice and applications (pp. 7-53). London: Routledge.

Penna, E. (2013). Epistemologia e método na obra de C G Jung. São Paulo: EducPuc.

Pilard, N. (2015). Jung and intuition: On the centrality and variety of forms of intuition in Jung and Post-Jungians. London: Karnac Books.

Progoff, I. (1953). Jung's psychology and its social meaning. New York: Dialogue House Library.

Rocha Filho, J. B. (2003). Física e psicologia. As fronteiras do conhecimento científico aproximando a física e a Psicologia Junguiana. Porto Alegre: EDIPUCRS.

Romanyshyn, R. D. (2007). The wounded researcher: Research with soul in mind. New Orleans: Spring Journal Books.

Samuels, A. (2008). New developments in the Post- Jungian field. Junguiana, 26, 19-27.

Shamdasani, S. (2006). Jung e a construção da Psicologia Moderna. São Paulo: Ideias e Letras.

Schmitt, A. (2011). A linguagem dos arquétipos: um diálogo entre a linguística cognitiva e a psicologia junguiana (Tese de Doutorado). Pontifícia Universidade Católica de São Paulo, São Paulo, SP, Brasil. Recuperado de http://www.sapientia. pucsp.br/tde_busca/arquivo.php?codArquivo=13689

Sherry, J. (2010). Carl Gustav Jung: Avant-garde conservative. New York: Palgrave Macmillan.

Schore, A. N. (2003). Affect regulation and the repair of the self. New York: Norton.

Stern, D. (1985). The interpersonal world of the infant: A view from psychoanalysis and developmental psychology. New York: Basic Books.

Zoja, L. (2005). Carl Gustav Jung como fenômeno históricocultural. Cadernos Junguianos, 1, 18-31.

Wahba, L.L. (2004). A sombra do antissemitismo. Jung e os anos 30. Junguiana, 22, 45-58.

Wahba, L.L. (2012). Psicologia Analítica. In R. Payá (Org.), Intercâmbio das psicoterapias (pp. 199-202). São Paulo: Roca. 